\title{
DILEMAS DO EMPRENDEDORISMO PESQUEIRO DE PEQUENO PORTE NO SUL DE SANTA CATARINA
}

\author{
BÚRIGO, F.L. \\ Departamento de Zootecnia e Desenv Rural, Centro de Ciências Agrárias, UFSC, \\ Florianópolis, SC - Brasil \\ Corresponding author: fabio.burigo@ufsc.br
}

\begin{abstract}
Búrigo, F.L. (2014) Dilemas do emprendedorismo pesqueiro de pequeno porte no sul de Santa Catarina. Braz. J. Aquat. Sci. Technol. 18(1):61-70. elSSN 1983-9057. DOI: 10.14210/bjast.v18n1.p61-70 This study analyzes the importance of fishing and aquiculture in southern Santa Catarina from the perspective of sustainable territorial development. An analysis model was developed to guide the research methodology. Preliminary studies indicate the existence of four value chains related to fishing and aquiculture in the territory, with products from industrial fishing, cottage fishing, shrimp farming and fresh water tanks. Although they function in articulation, these production chains have distinct structures and degrees of coordination, but they all act in an incipient manner in territorial development. The debilities in the institutional and organizational environments reveal the concentration of earnings among the agents that control the final phases of the production chains, demonstrating the need to include factors linked to the preservation of the ecosystems and strengthen ties of cooperation and the construction of companies that fortify the economic participation of the cottage fishermen.
\end{abstract}

Keywords: Fishing and aquiculture, sustainable territorial development, production chain.

\section{INTRODUÇÃO}

É possível superar a condição de pobreza de uma região sem depredar seus recursos naturais? Esse clássico trade-off, discutido em profundidade por Solow (1993), espelha bem o dilema de muitas regiões pesqueiras do Brasil. Muitas dessas zonas possuem atrativos turísticos expressivos, mas contam ainda com baixo indicadores em termos de desenvolvimento. Em função de sua fragilidade ambiental, aliada ao crescente processo de especulação imobiliária, que pressionam os seus recursos naturais, políticas públicas e outras iniciativas ligadas ao desenvolvimento precisam encontrar alternativas que viabilizem a reprodução social e econômica dos moradores locais. A crescente preocupação com a sustentabilidade, a expansão das políticas sociais e a atenção dada pelo governo federal ao setor pesqueiro, que resultou na criação de um ministério próprio, formam um cenário favorável ao desenvolvimento das regiões pesqueiras e aquicolas do país.

Porém, para alçarem os resultados esperados essas ações precisam ter uma alta compreensão sobre as potencialidades e limites existentes, fugindo de medidas paliativas que se revelam incapazes de proporcionar as transformações estruturais que essas áreas necessitam para se desenvolver. Em muitos projetos a pressuposta relevância social das iniciativas se sobrepõe a outros quesitos considerados chaves para o desenvolvimento sustentável. Por não considerar adequadamente as diferentes dimensões envolvidas nesses processos, muitas iniciativas de combate à pobreza em regiões rurais e pesqueira acabam subestimando o rigor das análises a respeito da viabilidade econômica, o impacto ambiental dos empreendimentos e da capacidade de gestão dos seus proponentes.

Este trabalho analisa o potencial do empreendedorismo pesqueiro e aquícola no Território Sul Catarinense. Essa região é integrada por dezenove municípios situados próximos ao chamado complexo lagunar. Seu recorte geográfico segue uma divisão regional estabelecida em 2009 pelo Ministério da Pesca e Aquicultura (MPA), que visa apoiar a construção de políticas territoriais de desenvolvimento nas áreas pesqueiras e aquícolas do país. O Sul Catarinense foi selecionado para este estudo em função da relevância do seu setor pesqueiro na dinâmica socioeconômica regional e da importância que essas atividades alcançam no plano estadual e nacional da pesca.

\section{MATERIAL E MÉTODOS}

A fundamentação teórica desse trabalho está calcada nos estudos da Nova Economia Institucional (NEI) e da Sociologia Econômica (SE). Por essas correntes "a vida econômica não pode ser entendida senão levando-se em conta as dimensões culturais e cognitivas das estruturas sociais e as instituições em que está inserida" (Panzutti, 2011, p.61). Busca-se avaliar as propostas de apoio ao desenvolvimento em territórios de pesca, tendo como referência a análise das cadeias produtivas e das cadeias de valor relacionados aos produtos pesqueiros presentes nessas regiões.

A noção de cadeia produtiva se consolida no Brasil a partir de duas vertentes teóricas distintas. 
A primeira tem origem nos Estados Unidos, onde os processos de transformação da agricultura e de seus desdobramentos socioeconômicos do Pós-Guerra passaram a ser analisados por meio de um enfoque sistêmico. Essa abordagem permite compreender melhor os componentes e processos que propiciam a transformação de matérias primas e dos demais insumos em produtos para os consumidores. Nessa ótica, cadeias são constituintes de um sistema resultado da articulação entre um conjunto de processos e da ação de instituições interligadas por objetivos comuns. Esse sistema maior, que engloba outros sistemas menores, ou subsistemas, foi chamado negócio agrícola, ou agribusiness (Davis \& Golberg, 1957).

A segunda tem origem na França, onde a noção de cadeia (filiere) de produção surge com a tentativa de decompor o sistema produtivo visando avaliar as capacidades produtivas específicas de uma região para promover seu desenvolvimento econômico, ambiental e social (Simioni, 2007; Morvan, 1998).

A partir dessas duas vertentes, cadeia produtiva pode ser definida como sendo o conjunto de componentes interativos, incluindo os sistemas produtivos, fornecedores de insumos e serviços, industriais de processamento e transformação, agentes de distribuição e comercialização, além de consumidores finais. Objetiva suprir o consumidor final de determinados produtos ou sub-produtos. Esses componentes estão relacionados a um ambiente institucional (leis, normas, instituições normativas) e a um ambiente organizacional (instituições de governo, de assistência técnica, de crédito etc.), que exercem influência sobre os componentes da cadeia e sobre o seu desempenho como um todo (Castro et al., 2002).

Os estudos ligados a NEI e a SE ajudam a entender como as organizações civis e entes governamentais se movimentam no interior das cadeias produtivas. Os agentes procuram organizar processos de coordenação para viabilizar suas transações. Os custos de transação afetam a performance relativa de diferentes formas de se organizar recursos e atividades de produção e estão presentes em diferentes intensidades conforme o ambiente institucional (Panzutti, 2011; North, 1992; Williamson, 2000).

A coordenação pode ser definida como "um processo adaptativo, gerado por mecanismos institucionais que produzem algum grau de ordem na interação entre os agentes" (Pondé, 2000, p.98). A busca por maior valor com os produtos processados e diferenciados e a necessidade de responder à crescente complexidade dos atributos tecnológicos amplia a necessidade de coordenação nas cadeias (Panzutti, 2011). Essa coordenação pode espelhar "relações de mando" e outros mecanismos de "controle hierárquico", e ser gerada por meio da atuação em diferentes elos das cadeias (Pereira et al., 2007).
Para esses autores, a coordenação é organizada a partir de objetivos específicos parametrizada por uma ou várias estruturas de governança. Governar a transação significa estabelecer comportamentos desejados e, conseguir efetivá-los a partir de um adequado processo de coordenação. Assim, as ações de governança apresentam relações com estruturas de poder que possuem a capacidade de formular regras para a ação dos agentes envolvidos na cadeia produtiva (Pereira et al., 2007). Segundo Volkmann \& Albert (2005) a governança de uma cadeia produtiva expressa o poder de estabelecer regras para os membros envolvidos, e a coordenação assegura a implementação e a aderência à essas regras.

Uma abordagem inspirada na noção de cadeia produtiva relaciona-as à construção das chamadas cadeias de valor. Utilizado pelo Programa Desenvolvimento Regional Sustentável (DRS) do Banco do Brasil (BB) esse conceito mostrou-se mais adequado para o estudo das atividades sócio-econômicas pesqueiras e de ações relacionadas às dinâmicas territoriais. Ao contrário das abordagens tradicionais sobre cadeia produtiva que estão focadas em um produto específico, pela ótica da cadeia de valor busca-se verificar o grau de complexidade das inter-relações de produtos correlatos e, consequentemente, das diferentes etapas ligadas à sua produção e distribuição (Banco do Brasil, 2009).

Para discutir as cadeias de valor relacionadas ao desenvolvimento é importante ter em conta as suas múltiplas dimensões. A visão multidimensional reforça a necessidade de se recorrer ao enfoque sistêmico para analisar suas potencialidades.

Além disso, quando colocada em prática, a idéia do desenvolvimento apresenta resultados heterogêneos, que dependem do grau de mobilização dos atores. Assim, o emprego dos recursos do território para finalidades produtivas por parte de empreendimentos econômicos tem efeitos e impactos diferentes e decisivos sobre a organização social e os ecossistemas (Abramovay, 2010).

Desse modo, sob o ponto de vista econômico, constitui-se um sistema de ação e de mobilização de recursos, em que o território não é visto apenas como um espaço delimitado geograficamente, mas fruto de uma construção social que se processa dentro deste ambiente pela ação de empresas, associações, grupos, etc. (Duarte, 2012).

No Brasil, a necessidade de fortalecer segmentos menos favorecidos está no centro do debate sobre desenvolvimento. Essa premissa também é chave para se pensar o futuro dos territórios pesqueiros e a construção de novas formas de organização econômicas das cadeias produtivas ali presentes (Delgado \& Leite, 2008). Para reverter a situação de 
pobreza presente é necessário superar as propostas tradicionais de crescimento econômico baseadas na exploração intensiva dos recursos naturais, gerando processos inovadores e sustentáveis de desenvolvimento (Enríquez, 2010).

A partir da articulação dos atores envolvidos é que se desenvolvem as ações econômicas ligadas às cadeias produtivas, ou seja, as atividades relacionadas à produção, distribuição e consumo (Bonnal \& Kato, 2011). Tendo em mente essa visão sobre a territorialização e articulação sistêmica das cadeias produtivas que as políticas públicas de apoio ao desenvolvimento devem orientar suas estratégias de fortalecimento de projetos econômicos.

Foi possível identificar quatro cadeias de valor relacionadas à pesca e à aqüicultura nos municípios que formam o Território Sul Catarinense: pesca industrial, pesca artesanal, carcinocultura e piscicultura de água doce. Inicialmente, integravam o Território os municípios de Garopaba, Laguna, Imaruí, Imbituba, Jaguaruna, Tubarão, Gravatal, Capivari de Baixo, Paulo Lopes, Pedras Grandes, Armazém, Treze de Maio e Sangão. Em 2009 foram acrescentados ao Território os municípios de Braço do Norte, Grão Pará, Rio Fortuna, Santa Rosa de Lima, São Martinho e Orleans.

Assim, o estudo teve como guia, de um lado, essas quatro cadeias de valor, e de outro, campos de análise contemplando dimensões e questões operacionais comumente consideradas nas abordagens territoriais. O cruzamento dessas variáveis levou a formulação de um conjunto de categorias e de indicadores que nortearam a análise (ver Quadro 1). Em função da importância social e dos desafios assumidos pelas políticas de desenvolvimento territorial em termos de inclusão socioeconômica da população pesqueira, dedicou-se, neste estudo, uma atenção especial à cadeia de valor da pesca artesanal.

As informações secundárias que subsidiam este estudo foram obtidas em órgãos do governo federal, estadual e municípios da região. Além disso, a investigação se debruçou em relatórios e projetos desenvolvidos por institutos de pesquisas e por organizações que exercem funções estratégicas no desenvolvimento socioeconômico (bancos, cooperativas, universidades, Sebrae, etc.).

A pesquisa foi complementada por diversas visitas in loco e 27 entrevistas diretas, envolvendo produtores familiares, líderes comunitários, sindicalistas, administradores de empreendimentos, empresários, gestores do governo estadual, extensionistas das empresas de assistência técnica, coordenadores de ONG, pesquisadores de universidades, prefeito, secretários municipais, vereadores e outras autoridades. Todas essas entrevistas foram semiestruturadas, seguindo um roteiro de questões pré-elaboradas, mas havendo espaços para manifestações espontâneas dos entrevistados. O estudo teve ainda acesso a mais quatorze entrevistas, realizadas por um estudante da UFSC que desenvolveu uma dissertação de mestrado a respeito da vida financeira de pescadores de Imbituba e Garopaba.

\section{RESULTADOS E DISCUSSÃO}

Os dezenove municípios que compõem o Território ocupam uma área de $4910 \mathrm{~km}^{2}$ no sudeste do Estado, o que representa 5,15\% do espaço geográfico estadual. Em 2010 havia 370633 habitantes na região, correspondentes a $5,93 \%$ da população catarinense e uma densidade demográfica de 75,4 habitantes por quilômetro quadrado, superior à média estadual $\left(67,7 \mathrm{hab} / \mathrm{km}^{2}\right)$. A maioria das localidades que compõe o Território Sul Catarinense está situada na região litorânea. Além de praias, alguns municípios possuem áreas de lagoas de água salgada. Várias dessas lagoas estão interligadas, formando um ecossistema específico e de grande extensão denominado Complexo Lagunar. Em muitas comunidades rurais do Território observa-se também a presença de lagoas artificiais e tanques de água doce, onde são desenvolvidos empreendimentos ligados à aquicultura (Muñoz, 2011).

A Superintendência Estadual do MPA indica que em 2011 havia 9592 pescadores registrados nos municípios que formam o Território, número que equivale a pouco menos de um terço do estado. Ressalte-se que o número de pescadores citados deve ser bem superior ao existente nos registros oficiais, pois existem muitas pessoas que pescam nas lagoas e nas praias sem a devida licença ou com uma carteira de pescador amador. Do total de registrados $44 \%$ é do sexo feminino, o que serve para desmistificar a idéia de que a pesca é uma profissão conduzida somente por homens. Com efeito, boa parte do processamento de frutos do mar (camarão e siri) e de pescado (filetagem) existentes na região é realizada por mulheres. Por outro lado, é possível que uma parcela das esposas e filhas de pescadores esteja registrada na atividade apenas para se habilitar aos benefícios sociais oferecidos à categoria, tais como o seguro defeso e a aposentadoria especial.

Dados do MPA revelam que, em 2008, 70\% dos pescadores não possuía o ensino fundamental completo, $7,7 \%$ concluiu o ensino médio e apenas vinte e cinco tinham curso superior. A baixa escolaridade reflete-se nos indicadores de desenvolvimento humano, na falta de perspectivas de crescimento sócio-econômico e na baixa qualidade de vida. 
Quadro 1 - Campos e principais indicadores de análise das cadeias de valor da pesca industrial e artesanal.

\begin{tabular}{|c|c|}
\hline Campos de análise & Indicadores \\
\hline Breve Diagnóstico & $\begin{array}{l}\text { - Informações sociais e econômicas } \\
\text { do Território }\end{array}$ \\
\hline Dimensão Econômica & $\begin{array}{l}\text { - Produção, beneficiamento e } \\
\text { - comercialização } \\
\text { - Participação no mercado } \\
\text { - Grau de formalidade das } \\
\text { atividades } \\
\text { - Mecanismos de gestão } \\
\text { - Estratégias de financiamento } \\
\text { - Infra estrutura existente }\end{array}$ \\
\hline $\begin{array}{l}\text { Dimensão } \\
\text { Sociocultural }\end{array}$ & $\begin{array}{l}\text { - Perfil dos empreendedores } \\
\text { - Normas formais e informais de } \\
\text { exploração das águas e outros } \\
\text { bens comuns }\end{array}$ \\
\hline Dimensão Ambiental & $\begin{array}{l}\text { - Impacto da atividade } \\
\text { - Projetos e políticas de proteção }\end{array}$ \\
\hline $\begin{array}{l}\text { Dimensão Político- } \\
\text { institucional }\end{array}$ & $\begin{array}{l}\text { - Formas de representação } \\
\text { - Governança do ambiente } \\
\text { institucional } \\
\text {-Gestão social do território } \\
\text {-Participação nas instâncias } \\
\text { colegiadas territoriais } \\
\text { - Tipologia dos empreendimentos e } \\
\text { das redes }\end{array}$ \\
\hline Questões auxiliares & - Economia Solidária \\
\hline
\end{tabular}

Fonte: elaborado pelo autor.

\section{Dimensão Econômica}

As cadeias de valor identificadas no Território Sul Catarinense possuem um razoável nível de integração econômica. No entanto, essa dinâmica de funcionamento é controlada por alguns atores ligados a pesca industrial que também manejam diversos elos das demais cadeias. Assim, a articulação entre as cadeias é pouco transparente em termos institucionais, visto que a maioria dos atores está pouco integrada em redes ou mesmo em organizações de cunho setorial. Por se tratar de uma área relativamente pouco expressiva na composição geral da economia e que conta com políticas públicas ainda em fase de construção, observa-se que os acordos comerciais presentes são efetuados de maneira informal e pouco equitativa.

No Sul Catarinense, a pesca artesanal apresenta uma grande importância social e econômica. As atividades de captura de pescado ocorrem tanto em mar aberto e baias como nas lagoas da região. Embora historicamente muito produtivas, nos últimos anos tem havido redução da quantidade e da qualidade dos estoques. Isso ocorre ao mesmo tempo em que a procura aumenta em função da expansão do turismo e das campanhas de incentivo ao consumo. Ressalte-se que o "camarão nativo de Laguna", é um produto bem conhecido em todo o Sul e Sudeste do Brasil.

A falta de informações consolidadas e confiáveis não permite quantificar corretamente quanto da produção artesanal percorre todos os elos da cadeia ao ser repassada aos intermediários e às indústrias, e nem a que é vendida diretamente aos consumidores e aos pequenos comerciantes locais, configurando a presença de cadeias curtas. As informações disponíveis dão conta, não obstante, que grande parte da produção artesanal é adquirida in natura pelos atravessadores (Costa et al., 1998). Acredita-se que boa parte da produção regional acabe se misturando à produção industrial, por força das redes de comercialização estabelecidas pelos atravessadores.

Não há registro de sistemas de comercialização de produtos pesqueiros para o mercado institucional (compras de produtos coordenada por órgãos públicos) e nem acordos formais entre os pescadores artesanais e empresas de grande e médio porte que atuam na área do consumo, como as redes de supermercados. A falta desses canais diretos de venda e de processos próprios de agregação sugere que a maior fatia da renda acaba nas mãos das indústrias pesqueiras, atravessadores e comerciantes do setor gastronômico.

Os arranjos existentes no Território indicam que a pesca de origem industrial é a cadeia mais significativa em termos de movimentação econômica - embora também não existam dados confiáveis sobre a produção e comercialização desses produtos. Além da produção trazida pelas capturas em oceano que são descarregadas no Terminal Pesqueiro de Laguna, o Território abriga diversas indústrias de processamento e empresas de revenda e de transporte de pescado. Apesar de grande crescimento, a maioria das empresas que atua na pesca industrial está ainda sob o controle familiar.

$\mathrm{Na}$ região, a carcinocultura concentra-se em tanques construídos em torno das lagoas do complexo lagunar. Depois de um período de forte expansão, nos últimos anos o cultivo intensivo de camarão sofreu um forte revés. Em seu auge, em 2003, a região possuía mais de duzentos empreendimentos, que no conjunto chegaram a produzir cerca de quatro mil toneladas. Mas o aparecimento de uma infecção viral, denominada de mancha branca, praticamente dizimou os criatórios, gerando grandes perdas financeiras aos empresários, agricultores e pescadores que investiram no setor. Apesar de não causar danos à saúde humana, a doença prejudicou fortemente a reprodução do camarão de cativeiro, inviabilizando a sua produção em escala comercial. Em Laguna, dos 66 produtores apenas sete permaneceram parcialmente ativos, gerando uma produção que não ultrapassa as dez toneladas.

Com o surgimento da mancha branca os institutos de pesquisa e laboratórios da região sul do Brasil passaram investir na busca de larvas de camarões resistentes à doença. Mas, as dificuldades técnicas e operacionais sugerem que a atividade poderá ser revigorada apenas no médio e longo prazo. 
No Sul Catarinense, a piscicultura de água doce é praticada preponderantemente pelos agricultores familiares. Atualmente, existem produtores que cultivam peixes para uso doméstico e para a comercialização esporádica. Notam-se também dezenas de produtores que começaram a desenvolver a atividade de maneira intensiva e durante todo o ano.

Um fator crucial na análise do mercado dos produtos de pesca são as interconexões que a pesca industrial estabelece com as demais cadeias de valor (pesca artesanal, carcinocultura e pescado de água doce). Parte dos produtos de origem artesanal e familiar é revendida pelos atravessadores às indústrias de processamento, ao mesmo tempo em que essas indústrias são abastecidas pela pesca industrial. Os intermediários articulam cestas com produtos oriundos da pesca industrial e da artesanal para abastecer pequenos mercados consumidores (restaurantes, bares, etc.) e as redes varejistas do estado.

Eventualmente, pescadores e comerciantes montam peixarias para comercializar produtos capturados e manipulados primariamente por suas famílias e repassar a produção adquirida junto aos vizinhos. Contudo, a maioria desiste pouco tempo depois, pois as vendas diminuem muito fora da temporada turística (verão). Além disso, os custos tributários e de manutenção dos equipamentos inviabilizam economicamente os empreendimentos.

Nota-se que existem duas formas principais de beneficiamento dos produtos de pesca artesanal. A mais comum é a manipulação primária, um tipo de processamento realizado informalmente há centenas de anos pelos moradores do Território: "um levantamento efetuado somente no município de Laguna por órgãos de vigilância sanitária do estado identificou a presença de cerca de 120 pontos de processamento clandestino de pescado (siri, camarão, peixe, etc.)" (depoimento de um extensionista da região). Somente os empreendimentos que adotam uma escala industrial efetuam a manipulação dos produtos dentro de padrões de sanidade exigidos pela legislação. Além disso, são esses mesmos empreendimentos que acabam sendo registrados e acompanhados em termos fiscais.

Boa parte dos itens vendidos pela pesca industrial do Território recebe alguma forma de processamento primário, sendo os mais comuns os congelados inteiros, postas, files, enlatados, salmouras e salgados (Costa et al., 1998). Contudo, nas épocas das safras da corvina, tainha e anchova diversos caminhões partem de Laguna para outras regiões do país com cargas de peixes frescos. Durante essas viagens, as empresas adquirem peixe e camarão de cativeiro de outros estados para amenizar seus custos de transporte e reabastecer pontos de comércio existentes no caminho. Produtos não comercializados voltam ao Sul para serem reaproveitados na região.
Por sua vez, a manipulação secundária de pescado é ainda muito rara na região, embora já existam muitos produtos de valor comercial que podem ser obtidos com esse tipo de beneficiamento e do reaproveitamento dos subprodutos.

As empresas de médio e grande porte da região desenvolveram estruturas de coordenação parcial das quatro cadeias de valor existentes no Território. Os detentores das maiores embarcações - denominados de armadores - são responsáveis pela maior parte do pescado que aporta em Laguna. Esse grupo seleto de empresários do município - cerca de sete ou oito famílias - detêm igualmente as principais unidades de processamento e domínio sobre os sistemas de comercialização e de transporte de pescado. Apesar das incertezas presentes, essa forma de coordenação proporciona inúmeras vantagens para o grupo, como a possibilidade de influenciar a formação dos preços de atacado do pescado e do camarão vendido no país.

Na carcinocultura, a produção é também quase toda direcionada às indústrias da região e ao mercado consumidor de Florianópolis. Em função da pequena expressividade dessa produção, os preços de mercado acabam sendo quase sempre ditados por outros agentes. Já os piscicultores de água doce demonstraram maior satisfação. Nos últimos anos, as associações municipais de aquicultura passaram a coordenar as negociações com as indústrias no sentido de estabelecer preços mínimos de compra do pescado de seus associados. Em alguns locais tais organizações estão conseguindo estabelecer acordos semelhantes com os fornecedores de insumos (alevinos e rações).

A maioria dos negócios realizados pelos pescadores artesanais do Sul Catarinense ocorre na informalidade, sem a emissão da nota de produtor. Os pescadores e suas famílias que manipulam primariamente o pescado ou comercializam diretamente esses produtos também não possuem empresas constituídas. De acordo com o Sebrae-SC, em 2009 existiam quinze estabelecimentos com serviços de inspeção federal ou estadual (SIF ou SIE).

Para aumentar a escala de produção, empresas de pescado e atravessadores contratam informalmente os ribeirinhos para efetuar o processamento primário de produtos locais e trazidos de fora. Essa estratégia é uma das responsáveis pela grande quantidade de pontos clandestinos de manipulação de pescado existentes no Território, bem como pelo incremento das vendas informais. É que os produtos descartados pelas indústrias, por estarem sem condições de serem beneficiados ou passarem por processos de congelamento, não atenderem as exigências comerciais em termos de tamanho, aparência, etc. acabam sendo repassados às redes de consumo (bares e restaurantes) pelos atravessadores ou pelas famílias que efetuam a manipulação. 
Além de não seguir os padrões sanitários, o trabalho é efetuado sem qualquer formalidade trabalhista ou fiscal pelos contratantes. Curiosamente, muitos pescadores artesanais não desejam regularizar sua carteira de trabalho para não perder os benefícios sociais destinados à sua categoria, como o seguro defeso. Essa situação também ocorre quando o pescador atua como trabalhador temporário em indústrias, lojas de comércio ou como embarcado em navios de pesca industrial.

Os pescadores artesanais combinam ações individuais e coletivas no exercício de suas atividades profissionais. Para pescar em mar aberto é necessário dispor de uma estrutura composta principalmente por uma equipe de cinco a nove pessoas (parelha), bar$c o$, redes e galpão para depositar os equipamentos. Embora seja formada quase sempre pelas mesmas pessoas, a equipe atua sem regulação sob o ponto de vista trabalhista, sendo a remuneração do trabalho efetuada em produto e seu valor estipulado sobre o montante capturado. Ou seja, numa pescaria desse tipo não há pagamento fixo, embora existam acordos tácitos sobre o modo de repartir o total da produção entre o proprietário dos equipamentos e os demais membros da equipe - essas normas informais sofrem pequenas variações dependendo do local. $\mathrm{Na}$ época da safra, além de participar da jornada no oceano, os membros da equipe assumem implicitamente 0 compromisso de fazer trabalhos de manutenção da embarcação e das redes durante os intervalos das pescarias. Penosidade, riscos e sazonalidade da atividade e a irregularidade das rendas obtidas, são os principais fatores que contribuem para o enfraquecimento desse mercado de trabalho.

Nas lagoas a cooperação está também presente na condução das atividades de pesca e na manutenção das "artes" (redes e outros utensílios). Contudo, as equipes são menores e a regras de divisão da produção são mais variáveis. Em muitos locais operam acordos informais efetuados pelos pescadores para delimitar as águas das lagoas destinadas à exploração produtiva. Porém as parcerias quase sempre são informais e não chegam às etapas do beneficiamento e da comercialização.

Explicações dadas pelos habitantes da região permitem concluir que essa situação deve-se a conjugação de fatores econômicos, físicos e culturais, intrínsecos à atividade pesqueira. Uma das questões é que o pescado é um produto perecível que necessita de imediato armazenamento, beneficiamento ou consumo. No momento, é mais viável desfazer-se das capturas pouco depois que o barco aporta na praia ou na beira das lagoas. Ademais, como as maiores safras de pescado ocorrem no inverno, portanto numa época de baixo consumo local, boa parte das capturas de verão acaba também repassada aos atravessadores, para preservar os canais de venda.

Quando o pescador efetua algum tipo de manipulação dos produtos capturados, somente realiza essa tarefa em pequena escala, contando com ajuda da família e de vizinhos. Um dos argumentos mais recorrentes para explicar as dificuldades de se montar um processo mais amplo de beneficiamento e de comercialização é de ordem sociocultural, pelo qual o comportamento desconfiado e individualista dos pescadores é inato. Contudo, a ação coletiva é uma prática comum entre os pescadores nas etapas da captura e de manipulação primária. A baixa cooperação em algumas etapas da cadeia produtiva pode ser explicada pelo fato de que a pesca é uma atividade extrativista e pouco reconhecida pelas políticas públicas e pela sociedade. Essa dificuldade de planejamento futuro em termos grupal é corroborado pelo baixo nível de educação formal dos pescadores, que reforça uma visão imediatista sobre sua vida econômica e profissional.

O imediatismo e a falta de uma visão de longo prazo diminuem quando os empreendimentos estão ligados à aquicultura e à maricultura (produção de ostras, mexilhões, etc.). Todavia, com exceção da carcinocultura, os cultivos planejados são pouco comuns na região. Grande parte da maricultura catarinense é praticada em áreas onde as águas são mais quentes.

Ademais, o custo para a constituição de um empreendimento de beneficiamento de pescado é muito elevado, devido ao porte mínimo exigido pela legislação sanitária atual. As explicações de ordem técnica, cultural ou econômico-social consolidam a percepção de que é mais prático e menos arriscado para os pescadores estabelecerem alianças com os intermediários. Além disso, muitos ranchos destinados à pesca artesanal acabam sendo usados irregularmente como abrigos para turistas ou como bares e restaurantes. A situação impede que pescadores e filhos de pescadores disponham de local adequado para as embarcações, dificultando o surgimento de novos empreendimentos.

A maioria dos pescadores artesanais não possui acesso aos serviços financeiros de qualidade, embora existam agências bancárias em quase todas as sedes municipais. Muitos pescadores artesanais não possuem títulos de seus imóveis, o que dificulta a apresentação de garantias contratuais.

De regra, o principal financiador do pescador artesanal é o atravessador. Além de fornecer crédito para necessidades profissionais e pessoais, o atravessador acaba prestando pequenos serviços ao pescador tais como: compra de peças e condução de equipamentos danificados para oficinas de conserto; aquisição e transporte de combustível para abastecer as embarcações nas praias e lagoas. A relação entre 
as partes é permeada por laços que ultrapassam o campo econômico, visto que o atravessador é também um morador da região. A proximidade estabelece uma dependência pessoal mútua, que pode se desdobrar no estabelecimento de acordos financeiros pouco convencionais. Por sua vez, alguns atravessadores mantêm relações semelhantes com os donos das indústrias de beneficiamento e de comercialização.

Nos últimos anos, alguns pescadores artesanais tiveram acesso ao microcrédito e aos empréstimos subsidiados. Muitos pescadores obtiveram financiamentos junto ao Programa Nacional de Fortalecimento da Agricultura Familiar (Pronaf) oferecido pelo Banco do Brasil. Na região, porém, essa medida não foi acompanhada por processos de educação financeira e nem esteve aliada a uma adequada prestação de assistência técnica aos empreendedores. Sabe-se que para muitos empréstimos foram adotados esquemas de aval solidário sem que os membros dos grupos tivessem conhecimentos ou confiança suficientes entre si - o aval solidário é uma forma de garantia em que três ou mais tomadores avalizam mutuamente os créditos concedidos. A elevação da inadimplência levou a interrupção do Pronaf e instalação de processos judiciais em vários locais do Território. Desde 2009, - Banco do Brasil de Laguna retirou parcialmente o embargo ao Pronaf devido ao DRS.

Nas demais cadeias de valor o acesso ao crédito e aos demais serviços financeiros assumem outros contornos. Na pesca industrial, quando não há disponibilidade nos programas específicos - como o Prófrota, muitas demandas acabam sendo atendidas por outras fontes devido ao interesse dos bancos em manter o cliente em função da reciprocidade. A carcinocultura avançou na região com o apoio do crédito, mas a crise da mancha branca levou a insolvência da maioria dos empreendimentos, gerando problemas nos financiamentos. Vários casos de inadimplência estão sendo discutidos na justiça. $\mathrm{Na}$ aquicultura de água doce, o problema dos financiamentos está diminuindo. Em muitas localidades, os piscicultores são ao mesmo tempo agricultores familiares e essa categoria vem obtendo avanços significativos em termos de oferta de crédito.

\section{Dimensão Sociocultural}

Existe uma gradativa queda do número de pescadores profissionais na região. Observa-se também uma falta de estímulos para a permanência dos jovens na atividade. Embora decrescente, em alguns municípios do Território, a pesca exerce ainda um importante papel social, visto ser um dos setores que mais disponibiliza empregos formais e informais, seja nas atividades de captura, como nas de beneficiamento e de comercialização. Além disso, muitos trabalhadores das indústrias são considerados pescadores artesanais, pois eles e suas famílias exploram as águas da região em determinadas épocas do ano.

Observa-se um interesse crescente dos agricultores familiares e de empreendedores ligados ao turismo rural pela aquicultura de água doce, que vem ocupando espaços agrícolas tradicionais.

Durante o verão, os pescadores artesanais alugam parte de suas propriedades aos veranistas, outros trabalham em bares, restaurantes ou como segurança de pontos comerciais e residências. Há também os que buscam apoio em empregos temporários junto às empresas de processamento de pescado e os que atuam como embarcados nas capturas de oceano. $O$ incremento monetário supre a queda dos rendimentos da pesca no verão.

\section{Dimensão ambiental}

De maneira geral, a pesca não é exercida em áreas particulares, mas em espaços considerados um "bem comum", onde os estatutos de posse e de uso não estão claramente definidos. Sabe-se que a exploração das águas está delimitada por códigos informais, historicamente construídos. O funcionamento desses normativos é um tema ainda pouco estudado na região, embora seja fundamental para se planejar o uso das áreas produtivas comuns.

$\mathrm{Na}$ ótica dos pescadores artesanais e dos gestores das políticas públicas, entre os problemas ambientais mais importantes do Território estão: i) pesca predatória e sobre exploração dos estoques pesqueiros nas áreas costeiras e nas lagoas; ii) descarregamento concentrado de água doce nas lagoas por conta dos plantios de arroz irrigado; iii) rejeitos despejados pelo Rio Tubarão oriundos das minas de carvão localizadas no Sul do estado; e iv) esgoto produzido pelos aglomerados urbanos que são jogados nas lagoas sem o devido tratamento. Especialmente na área do complexo lagunar, a somatória desses problemas acaba afetando a qualidade e a salinidade das águas das lagoas, afugentando os peixes e camarões para o oceano.

É recorrente a queixa de que os barcos de pesca industrial continuam operando em águas destinadas à pesca artesanal (próximas da costa). As embarcações ocupam esses espaços para a captura de pescado e para a coleta de iscas vivas. Outra reclamação são os aparelhos ilegais empregados pelos diferentes tipos de pesca: submarina, esportiva, industrial e artesanal. Muitas vezes capturam-se indevidamente espécies de baixo valor comercial, mas importantes na vida marinha e manutenção de suas cadeias alimentares.

O Território integra uma área de proteção ambiental (APA) aprovada por ser estratégica para a reprodução da Baleia Franca (Eubalaena australis), 
e por abranger ecossistemas de floresta quaternária, dunas, praias, restingas e ecossistemas marinhos (Martins, 2008). O processo de criação da APA e a recente discussão sobre a instalação de uma reserva extrativista marítima que atingirá lagoas acabaram gerando conflitos entre ambientalistas e pescadores.

Por vezes, tais divergências são fruto de interesses econômicos antagônicos. Novos proprietários de terrenos nas orlas e encostas usam o argumento da conservação do patrimônio natural para dificultar o acesso de pescadores (e turistas) às praias e outras regiões preservadas. Ocasionalmente, acabam obtendo a adesão de ambientalistas e de segmentos da população urbana local sensível à causa ecológica. Há queixas também sobre a postura de alguns ativistas, que elaboram projetos sem a devida participação da comunidade de pescadores. Por outro lado, há reclamações sobre os pescadores artesanais que continuam desrespeitando o período do defeso das espécies e utilizando de redes e malhas proibidas pela legislação.

A queixa mais ouvida no Território diz respeito à falta de fiscalização dos aparelhos do Estado para cumprir as normas ambientais e de exploração. Ao mesmo tempo o Território registra uma presença crescente de órgãos governamentais dedicados à defesa do meio ambiente. Alguns desses organismos têm uma postura ativa, mas suas ações são pouco coordenadas ou insuficientes para evitar os danos ambientais e limitar práticas predatórias.

Geralmente, os embates ambientais mais graves são resolvidos na esfera jurídica. Uma exceção é a articulação criada pelo Fórum ambiental do complexo lagunar, que tem mobilizado diversas entidades civis e órgãos públicos.

\section{Dimensão político-institucional}

Sabe-se que a entidade sindical mais conhecida no setor pesqueiro brasileiro é a colônia de pescadores. Além de colaborar com o governo na emissão de carteiras de pescador e no fornecimento de licenças para a pesca de espécies controladas, as colônias exercem funções tradicionais de defesa da categoria, ligadas principalmente aos aspectos previdenciários e fornecimento de alguns serviços médicos e jurídicos. Mesmo junto aos seus associados há muitas críticas sobre a atuação e a inoperância das colônias.

Além das colônias, alguns municípios do Território possuem atuação de sindicatos patronais e de sindicatos de trabalhadores da área da pesca. A organização sindical empresarial mais expressiva na região tem como área de abrangência a faixa litorânea sul, de Passos de Torres à Grande Florianópolis. A força econômica e a articulação política dos empresários fazem com que suas aspirações e demandas cheguem rapidamente aos gestores públicos.

Os sindicatos de trabalhadores representam os empregados junto às empresas da pesca industrial e às unidades de processamento e comercialização. Em geral, os sindicatos concentram sua atuação na defesa dos direitos dos embarcados junto aos armadores, na melhoria dos salários, criação de empregos, condições de trabalho e em litígios na justiça trabalhista.

No Território, as cooperativas que possuem algum tipo de vínculo com a pesca atuam no ramo da prestação de serviços, da produção pesqueira e do crédito. A única cooperativa de prestação de serviços existente é integrada por trabalhadores do Terminal Pesqueiro de Laguna. Na área de produção há registro de duas cooperativas. A primeira foi constituída por carcinocultores, mas está quase inativa devido ao problema da mancha branca. Em 2007 foi constituída a outra cooperativa na região com apoio do Programa DRS-BB e da Pastoral da Pesca, tendo como base social os pescadores artesanais. Em 2010 contava com 160 associados e um escritório na cidade de Laguna. Embora o seu planejamento preveja a construção de unidades de recepção municipais e uma unidade regional de beneficiamento, até 2012, a Cooperativa não conseguiu colocar seus projetos em andamento.

As cooperativas de crédito mútuas (urbanas) e rurais estão presentes em quase todos os municípios do Território. Porém, mesmo as rurais não priorizam o atendimento aos pescadores artesanais, uma vez que sua base social e história de constituição estão ligadas ao segmento dos agricultores. Por outro lado, a fragilidade organizacional dos pescadores e a falta de um ambiente institucional favorável dificultam a integração.

As associações são divididas em dois tipos em termos de arranjo institucional. Um grupo é formado por produtores familiares que praticam aquicultura em tanques e açudes instalados em suas propriedades rurais. São associações municipais que além de representar os interesses dos produtores junto aos órgãos públicos e privados (crédito, assistência técnica, etc.) estão buscando meios de aumentar a renda e o poder de barganha dos associados, envolvendo-se na compra de insumos e na comercialização do pescado.

O outro é composto por associações de pescadores artesanais, residentes das áreas litorâneas. São formadas por moradores de uma comunidade ou de um conjunto de comunidades vizinhas, agindo principalmente como elemento de ligação política entre as vilas de pescadores e os poderes constituídos. As mais atuantes desenvolvem lutas ligadas ao campo social, jurídico e na criação de infra estrutura. Não há projetos de fomento econômico ou de organização de empreendimentos coletivos dos pescadores, embora 
algumas tenham obtido recursos para a reforma de galpões (ranchos de pesca) e compra de equipamentos, guinchos e outros materiais de pesca. Ressalte-se que quase todos os locais da região são atendidos por escritórios de assistência técnica, que são vinculados ao governo de estado ou às prefeituras. $O$ público prioritário desses órgãos são os agricultores, embora existam algumas ações destinadas aos pescadores.

As experiências de economia solidária são ainda muito frágeis no Território. Nos últimos vinte anos, a Igreja Católica desenvolveu ações de conscientização, motivação e organização dos pescadores artesanais. Além de formação de lideranças e entidades comunitárias, nos últimos anos a Pastoral da Pesca passou a animar a constituição da Cooperlagunar. As experiências mais significativas são desenvolvidas pelas organizações do Sistema de Cooperativa de Credito Rural de Interação Solidária - Sistema Cresol. Existem diversas unidades Cresol na região, porém a grande maioria atende apenas os agricultores familiares. A organização que possui o maior número de pescadores associados é a Cresol Imaruí.

\section{CONCLUSÕES}

Este estudo permite concluir que o Território Sul Catarinense não abriga cadeias ou sistemas produtivos consolidados no setor da pesca, embora a cadeia de valor da pesca industrial já se configure como um arranjo produtivo local e as demais se encontrem na condição de aglomerados.

Por outro lado, é preciso ir além dos estereótipos que classificam os pescadores artesanais como uma categoria intrinsecamente desunida, em que laços de dominação estão presentes em elevado grau. Essas características criam uma espécie de determinismo psicossocial de que é muito difícil agir no sentido de que processos de cooperação econômica complexos floresçam entre os pescadores.

A criação de experiências descentralizadas permite aos protagonistas acumularem força política e econômica e conhecimento técnico e gerencial para construir novos arranjos institucionais e empreendimentos econômicos coletivos mais amplos.

Acredita-se que muitas ações dos pescadores industriais têm efeitos importantes nos rumos do território. A relação dos empreendimentos da pesca industrial com outros setores da economia e com o ambiente externo é muito mais forte do que nas demais cadeias.

Além da viabilidade econômica, os empreendimentos coletivos regionais da pesca artesanal dependem de uma boa sustentação em termos de "capital social" (Baqueiro, 2003). Muitos dos insucessos nas iniciativas associativas e cooperativas são gerados pela falta de experiência e pela baixa confiança entre as organizações e grupos que operam na escala local. Isso aumenta a insegurança para se planejar empreendimentos coletivos, com impacto no plano regional.

As características sócio-culturais da pesca e do público, aliada a queda da produção nas águas e a falta de estímulos (crédito, assistência técnica) são elementos que colaboram para que organizações econômicas mais complexas e a formalização empresarial não se concretizem no meio dos pescadores artesanais. Tais fatores indicam que as políticas de apoio à expansão da atividade pesqueira poderão esbarrar em limitações ambientais, técnicas, administrativas e institucionais. Esse é mais um argumento a favor de que as políticas públicas e as ações de desenvolvimento territorial priorizem as cadeias produtivas vinculadas à pesca artesanal de maneira estratégica e integrada, como também que os projetos públicos fortaleçam seus empreendimentos e a cooperação no campo econômico-produtivo. Para gerar ganhos significativos e duradouros tais ações precisam afetar positivamente o mercado da pesca e consequentemente a rentabilidade gerada em determinadas elos das cadeias envolvidas.

Programas de fortalecimento de empreendimentos na pesca artesanal devem ser concebidos sob a lógica de proximidade. É necessário estimular os estudos sobre o potencial de empreendimentos em termos de tamanho, produção e de investimento financeiro. Além de auxiliar a constituição de empresas familiares e comunitárias, deve-se apostar na geração de confiança e competência gerencial nos próprios beneficiários.

A readequação do Pronaf-Pesca e de outros programas de empréstimos governamentais deve facilitar o acesso dos pescadores artesanais e reduzir a inadimplência. Ao mesmo tempo devem-se organizar cursos de educação financeira e de aplicação correta dos recursos. A criação de organizações financeiras e programas de crédito com enfoque na pesca artesanal pode reproduzir os resultados já alcançados no meio rural, estimulando a implantação de postos de atendimento e novas cooperativas de crédito solidárias junto às comunidades de pescadores. Ao mesmo tempo, é importante articular, quando possível, a entrada dos pescadores e aquicultores no quadro social das cooperativas existentes. Em termos econômicos, os pescadores artesanais precisam agregar valor aos seus produtos e ampliar os canais de comercialização. Análises sobre o mercado, elaborados pelo Sebrae-SC, apontam várias formas de se agregar valor aos produtos pesqueiros da região. É preciso desenvolver estudos sobre o potencial de integração da aquicultura de água doce com as indústrias de beneficiamento de pescado, 
de modo a aumentar a integração setorial. A questão ambiental assume uma relevância particular no setor pesca. Em determinados ecossistemas, os problemas ambientais gerados por outras atividades (agricultura, especulação imobiliária, etc.) estão afetando fortemente a produtividade atual e futura do setor pesqueiro, e em outros, os estoques estão sendo reduzidos em função do manejo inadequado dos recursos. Para tentar contornar estas dificuldades é necessário estabelecer discussões nos espaços de articulação institucional propondo a implantação de mecanismos que estimulem a participação comunitária na fiscalização e controle das áreas de pesca.

\section{REFERÊNCIAS}

Abramovay, R. 2010. Para uma teoria dos estudos territoriais. In: Vieira, P. F.; Cazella, A.; Cerdan, C. \& Carrière, J-P. (ed.). Desenvolvimento territorial sustentável no Brasil: subsídios para uma política de fomento. Aped/Secco Florianópolis. 27- 47pp.

Banco do Brasil. 2009. DRS. Disponível em: < http://www. bb.com.br/portalbb/page3,8305,8368,0,0,1,6.bb?cod igoMenu=15244\&codigoNoticia=28552\&codigoRet= 15306\&bread=1>. Acesso em: 10 jun. 2014.

Baquero, M. 2003. Construindo uma outra sociedade: o capital social na estruturação de uma cultura política participativa no Brasil. Rev. Sociol. Polit. 21: 83-108.

Bonnal, P. \& Kato, K. 2011. O processo contemporâneo de territorialização de políticas e ações públicas no meio rural. In: Miranda, C. \& Tiburcio, B. (ed.). Políticas públicas, atores sociais e desenvolvimento territorial no Brasil. IICA Brasilia. 61- 82 pp.

Castro, A.M.G. de; Lima, S.M.V. \& Cristo, C.M.P.N. 2002. Cadeia produtiva: marco conceitual para apoiar a prospecção tecnológica. In: Simpósio de Gestão de Tecnologia, 22. Salvador. Anais... FEA/USP, São Paulo, 2002.

Costa, S. W. da; Grumann, A.; Oliveira Neto, F. M. de \& Rockzanski, M. 1998. Cadeias produtivas do estado de Santa Catarina: aquicultura e pesca. Epagri, Florianópolis. Boletim Técnico 97.

Delgado, N. G. \& Leite, S. P. 2011. Gestão social e novas institucionalidades no âmbito da política de desenvolvimento territorial. In: Miranda, C. \& Tiburcio, B. (ed.). Políticas públicas, atores sociais e desenvolvimento territorial no Brasil. IICA Brasilia. 89-130pp.

Davis, J.H. \& Goldberg, R. 1957. Aconcept of agribusiness: division of research. Graduate School of Business Administration. Harvard University, Boston, 257p.

Duarte, K. 2012. Desenvolvimento territorial sustentávele inovações sociofinanceiras no Litoral Sul Catarinense: Cresol Garopaba. Trabalho de Conclusão de Curso. Universidade Federal de Santa Catarina. 95f.
Enríquez, M. A. 2010. Trajetória do desenvolvimento: da ilusão do crescimento ao imperativo da sustentabilidade. Garamond, Rio de Janeiro. 389p.

Martins, A. 2008. Plano de ação participativo - Conselho Gestor da APA BF 2009-2010. Brasília. Relatório. Produto 03 da consultoria técnica prestada ao Projeto PNUD/BRA/00/009 - 273 - Proecos - Consultoria: Capacitação dos Conselheiros e Membros dos Grupos de Trabalho e Câmaras Técnicas do Conselho Gestor da APA-BF, no período de julho a dezembro de 2008.

Ministério da Pesca e Aqüicultura. 2009. Informações complementares para a realização do estudo. MPA Brasília, 3p.

Morvan, Y. 1998. Fondements d'economie industrielle. Economica, Paris. 255p.

North, D. C. 1992. Institutions and economic theory. Am. Econ. 36 (1): 3-7.

Muñoz, E. F. P. 2011. Dinâmica econômica da aquicultura e pesca - Território Sul Catarinense. Ministério da Pesca e Aquicultura, Florianópolis. 103p.

Panzutti, N. P. M. 2011. Mercado como construção social da realidade. Inform. Econôm. 41(7): 60-72.

Pereira; L. B.; Souza, J. P. \& Cário, S. A.F. 2007. Elementos básicos para estudos de cadeias produtivas: tratamento teórico-analítico. In: Prado, I. N.\& Souza, J. P. Cadeias produtivas: estudos sobre competividade e coordenação. Eduem Maringá.13-34 pp.

Pondé, J. L. S. P. 1993. Coordenação e aprendizado: elementos para uma teoria das inovações institucionais nas firmas e nos mercados. Dissertação de Mestrado. Universidade Estadual de Campinas UNICAMP. $134 f$.

Simioni, F. J. 2007. Análise diagnóstica e prospectiva da cadeia produtiva de energia de biomassa de origem florestal no Planalto Sul de Santa Catarina. Tese de Doutorado. Universidade Federal do Paraná - UFPR. 131p.

Solow, R. 1993. An almost practical step toward sustainability. Resources Policy 19 (3): 162-172.

Volkmann, E. \& Albert, H. 2004. Knowledge management in value chains. In: Newsletter of the sector project knowledge system in rural areas. Services for rural development GTZ. 11(mar.).

Williamson, O. E. 2000.The new institutional economics: taking stock, looking ahead. J. Econ. Lit. 38 (3): 595-613.
Submetido: Setembro/2012 Revisado: Setembro/2013 Aceito: Outubro/2013 